\title{
INHALT
}

Vorwort

VII

\section{KAPITEL: EINFÜHRUNG}

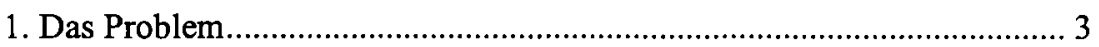

2. Zum aktuellen Forschungsstand ........................................................ 5

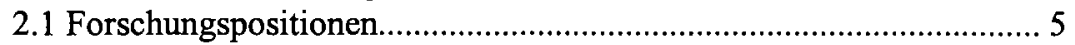

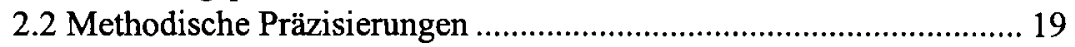

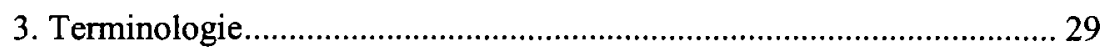

4. Der unter dem Begriff ,Frühjudentum“ gefaßte sachliche Gegenstand

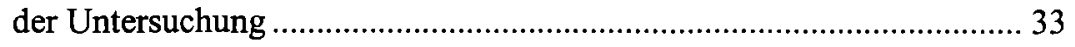

II. KAPITEL: FUNDIERUNG: GOTT ALS KÖNIG

1. Altes Testament (Hebräischer Kanon) ...................................................... 41

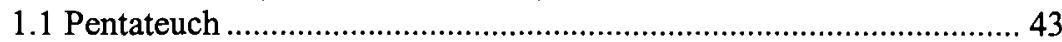

1.2 Die Bücher Josua bis 2 Könige (Frühere Propheten) ........................ 47

1.3 Die Bücher der Propheten ................................................................ 49

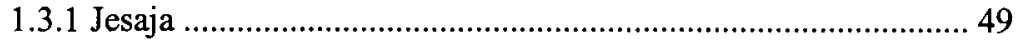

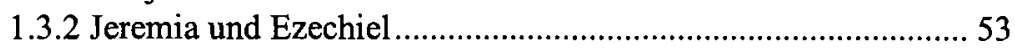

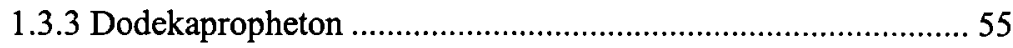

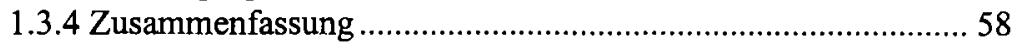

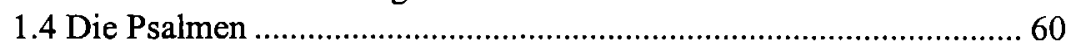

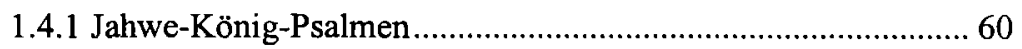

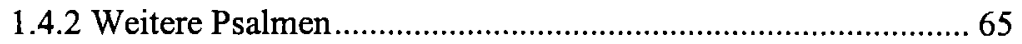

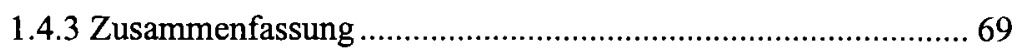

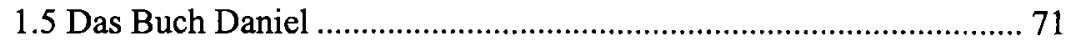

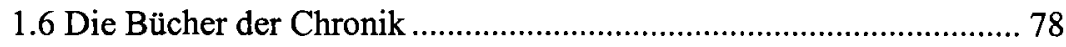

1.7 Ergebnisse: Gott als König im Alten Testament.................................. 80

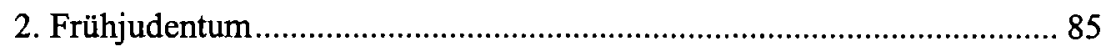

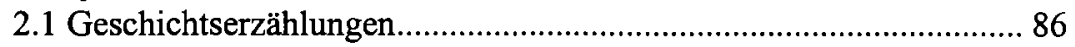

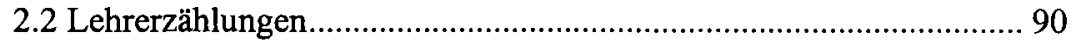

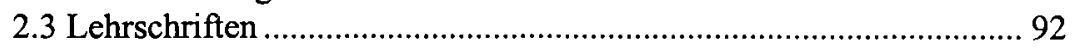




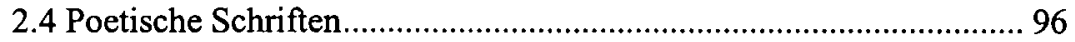

2.5 Schriftrollen von Qumran ............................................................. 99

2.6 Apokalyptische Schriften .............................................................. 111

2.7 Philo von Alexandrien und Josephus Flavius ................................. 121

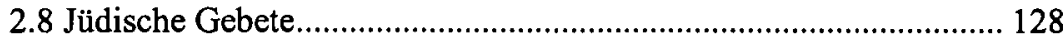

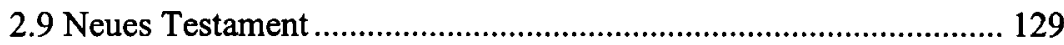

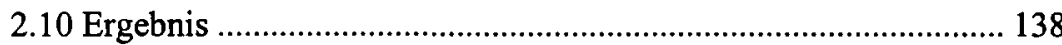

\section{KAPITEL: KÖNIGLICHE GESALBTENERWARTUNGEN IM JUDENTUM UM DIE ZEITENWENDE}

1. Alttestamentliche Ermöglichung ........................................................ 145

2. Politisch umgesetzte Beanspruchungen der Königstradition.................. 155

3. Die geschichtliche, davidisch-königliche Gesalbtenerwartung

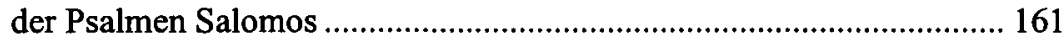

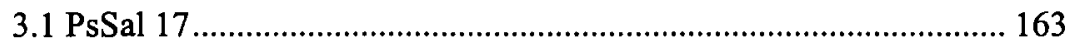

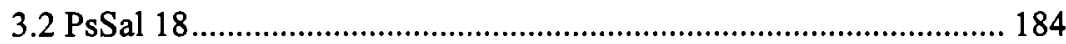

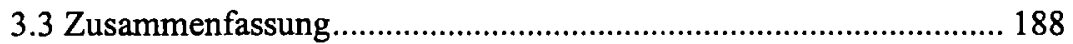

EXKURS: Königliche Motive in der jüdischen Weisheitstradition .......... 191

4. Der herrscherliche Gesalbte innerhalb der Erwartung zweier

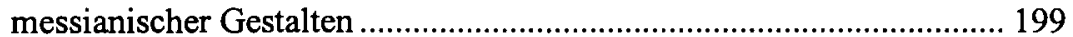

4.1 Die Schriften der Qumran-Gemeinschaft....................................... 199

4.1.1 Gesalbte(r) Aarons und Israels .............................................. 200

4.1.2 Fürst der Gemeinde und Sproß Davids ................................... 214

4.1.3 Terminologisch offene und nicht auswertbare Texte ............... 230

4.1.4 Fazit .......................................................................... 239

4.2 Die Testamente der zwölf Patriarchen ........................................... 245

5. Mangelnde Evidenz: Die Sibyllinischen Orakel.................................. 259

5.1 Buch 3 der Sibyllinen...................................................................... 260

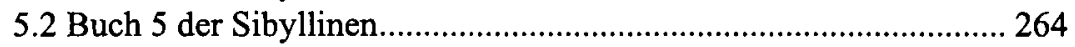

6. Die endzeitliche Gestalt eines „Menschen“ bei Philo von Alexandrien

7. Potentielle realpolitische Prätentionen auf die Königsherrschaft

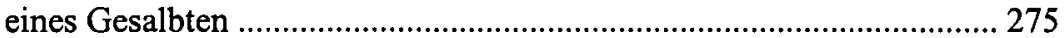

7.1 Aufstandsführer in der Darstellung bei Josephus Flavius................ 275

7.1.1 Religion und Revolution: Der biographische Hintergrund ..... 275

7.1.2 Texte und Gestalten.............................................................. 283

7.1.2.1 Im 1. Jh. n.Chr. vor dem jüdisch-römischen Krieg ............ 283

7.1.2.2 Während der Zeit des jüdisch-römischen Krieges.............. 295 
EXKURS: Jüdische Münzen aus der Zeit des jüdisch-

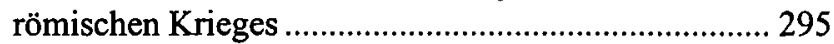

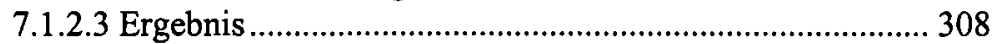

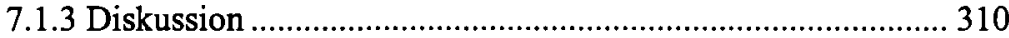

7.2 Ausblick: König Lukuas und Simon bar Kochba ............................. 317

8. Apokalyptische Variationen................................................................ 323

8.1 Das äthiopische Henochbuch ........................................................... 324

8.1.1 Die Bilderreden des äthiopischen Henoch .............................. 324

8.1.2 Das Buch der Traumvisionen ............................................... 343

8.2 Das vierte Buch Esra...................................................................... 346

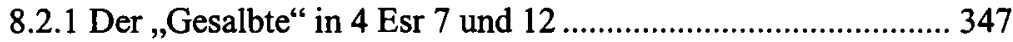

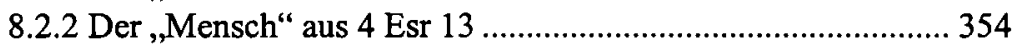

8.3 Die syrische Baruch-Apokalypse ...................................................... 363

8.4 Die Offenbarung des Johannes..................................................... 374

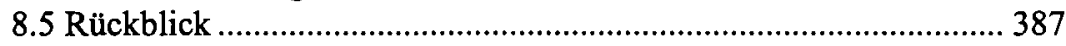

9. Nachklänge: Achtzehngebet und Targumim ....................................... 391

9.1 Spiegelungen des Volksglaubens im Achtzehngebet

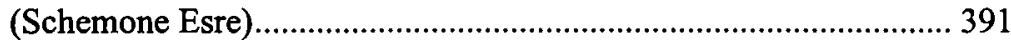

9.2 Bewahrung und Umprägung: Die Targumim ................................. 394

10. Jesus als königlicher Gesalbter im Neuen Testament......................... 405

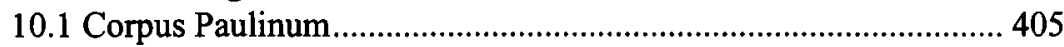

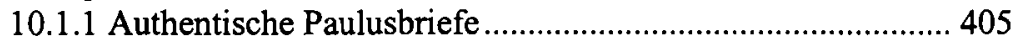

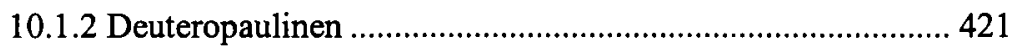

10.2 Synoptische Evangelien und Apostelgeschichte........................... 425

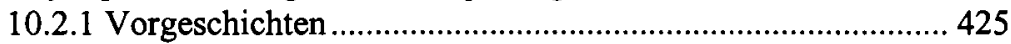

10.2.2 Evangeliencorpora................................................................. 430

10.2.3 Passion und Erscheinungen Jesu ......................................... 438

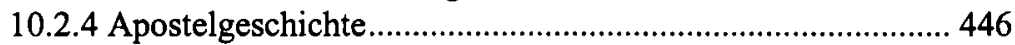

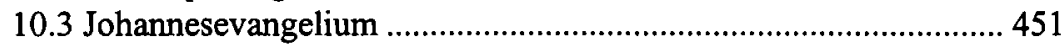

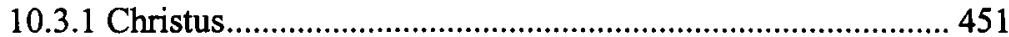

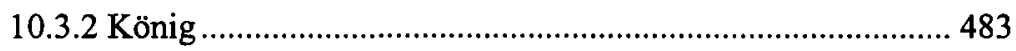

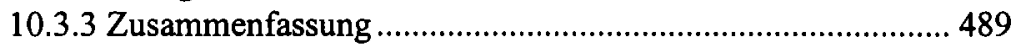

10.4 Fazit: Zur Entwicklung von Jesus zum Christus........................... 490

11. Die Frage nach weiteren korrelierten Titeln und Vorstellungen.......... 497

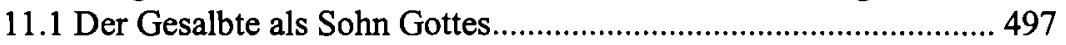

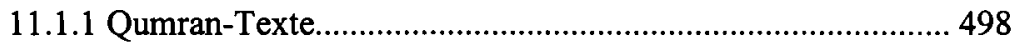

11.1.2 Texte im Verdacht christlicher Interpolation ........................ 508

11.1.3 Texte aus dem Neuen Testament............................................ 511

11.2 Leiden und Tod des Gesalbten .................................................. 512 


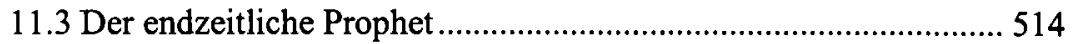

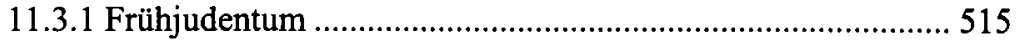

11.3.2 Jesus als endzeitlicher Prophet: Ein Überblick zur neutestamentlichen Erzählliteratur....................................... 527

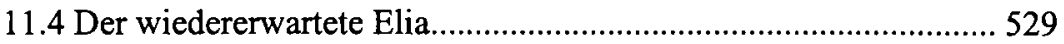

IV. KAPITEL: ERGEBNIS: DER KÖNIGLICHE GESALBTE IM FRÜHJUDENTUM

1. Zusammenfassung: Grundkonzeption und Variationen.......................... 537

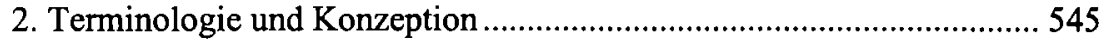

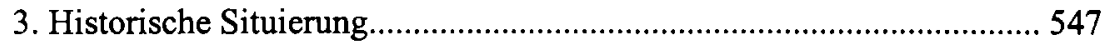

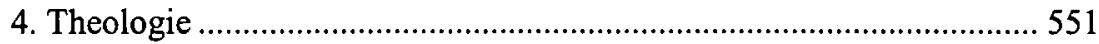

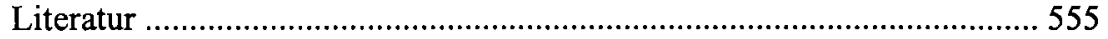

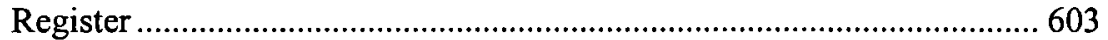

